\title{
Shaping Social Innovation in Local Communities
}

\author{
Roberto Cibin \\ Madeira Interactive Technologies \\ Institute (M-ITI), Funchal, Portugal \\ roberto.cibin@m-iti.org \\ Conor Linehan \\ School of Applied Psychology, \\ University College Cork, Cork, \\ Ireland \\ conor.linehan@ucc.ie
}

The Contribution of Intermediaries

\author{
Sarah Robinson \\ School of Applied Psychology, \\ University College Cork, Cork, \\ Ireland \\ sarah.robinson@ucc.ie

Laura Maye
School of Computer Science and
Information Technology, University
College Cork, Cork, Ireland
laura.maye@ucc.ie \\ Laura Maye
}
Christopher Csíkszentmihályi
Information Science, Cornell
University, Ithaca, New York
cpc83@cornell.edu

\begin{abstract}
Participatory social innovation projects often involve the coming together of design researchers, community development groups, and community members to develop (often technological) solutions to social problems or challenges. "Intermediaries" are specific individuals and organisations who contribute to these projects by translating intentions, values and experiences between design researchers and communities. Previous research has not yet critically examined the role of intermediaries in such projects. This paper does so in a project carried out in rural areas of Europe, which sought to test and develop a technology to support the creation of FM community radio stations in isolated areas. We present the project as a biography of infrastructures to provide an account of intermediaries' interactions during the project's unfolding. We find that how intermediaries shape the social base and ends of the project, and the interpretation of the technology involved, is influenced by their position, goals, and relationships in the process.
\end{abstract}

\section{CCS CONCEPTS}

- Human-centered computing $\rightarrow$ Collaborative and social computing; Empirical studies in collaborative and social computing.

\section{KEYWORDS}

Social Innovation, Intermediaries, Participatory Design, Community Radio

\section{ACM Reference Format:}

Roberto Cibin, Sarah Robinson, Maurizio Teli, Conor Linehan, Laura Maye, and Christopher Csíkszentmihályi. 2020. Shaping Social Innovation in Local Communities: The Contribution of Intermediaries. In Proceedings of the 11th Nordic Conference on Human-Computer Interaction: Shaping Experiences, Shaping Society (NordiCHI '20), October 25-29, 2020, Tallinn, Estonia. ACM, New York, NY, USA, 12 pages. https://doi.org/10.1145/3419249.3420178

Permission to make digital or hard copies of part or all of this work for personal or classroom use is granted without fee provided that copies are not made or distributed for profit or commercial advantage and that copies bear this notice and the full citation on the first page. Copyrights for third-party components of this work must be honored.

For all other uses, contact the owner/author(s).

NordiCHI '20, October 25-29, 2020, Tallinn, Estonia

(C) 2020 Copyright held by the owner/author(s).

ACM ISBN 978-1-4503-7579-5/20/10.

https://doi.org/10.1145/3419249.3420178

\section{INTRODUCTION}

This paper contributes to the debate on HCI and social innovation. Drawing from research on innovation in commercial contexts, we show the importance of considering the influence of "intermediaries", actors who connect the world of design and development of technology with its use in participatory social innovation projects. This contribution highlights to design researchers and practitioners the importance of relationships with intermediaries which we believe will increase the potential of participatory social innovation.

Social innovation is a process concerned with "innovations that are social both in their ends and in their means" [44:35]. Previous research (e.g. [30]) underlined how innovation is not just the sum of processes of ideation, design, and development of an artefact, but also is the result of the way this artefact is distributed and adopted by people in their daily life. A good product, service, or method is not innovative if it is not used. However, HCI researchers have not focused on how artefacts become distributed and adopted. More attention to innovation processes could narrow the gap between research and practice [48] increasing the consideration of "business factors" [30], namely how technology is commercialised and received in the market. Several scholars $[2,3,12]$ illustrate how a linear model of innovation that starts from design and arrives to diffusion is an exception, and that the adoption of specific innovations is often the result of messy processes. In fact, the different phases of innovation, as articulated by linear models, are usually intertwined, as are the actors involved [49], and this means that "the user, as well as all the intermediaries in development and production, participate in the design work" [12:3].

There is much research that tries to understand the role of design professionals in respect to social innovation, taking into account the widespread adoption of design practice by varied social actors [39, 40]. Such studies include Manzini's distinction between top-down and bottom-up social innovation, the former referring to projects started and driven by experts and professionals, the latter to projects started and driven by communities [38]. Research also interpreted design processes, including the position of designers in relation to institutions and communities [24] and the different strategies and tactics available to designers, communities, and organizations, throughout the design process $[36,56]$. Nevertheless, little attention has been given to the role of intermediaries, and this paper aims to 
contribute to this gap through exploring their contribution to the design process.

More specifically, in this paper we focus on the role of intermediaries in influencing the process that links the conception and development of a digital social innovation to its practical dissemination. Intermediaries are defined as "translators of interests and meaning between worlds of design and use" [54]. We will show how intermediaries are usually investigated within commercial contexts, as in Participatory Innovation [8-10], while considered only marginally in participatory social innovation with, and for, communities. We concentrate on geographical communities, as "communities that focus on physical features (space, location, boundaries)" [15:2]. We are aware of the plurality of interests, histories and goals present in communities as social constructs [35] and how the research process contributes to particular relationship configurations between and within these groups, based on the actors involved, their interests, and the negotiation of goals.

To discuss these topics, we describe the divergent results of two field deployments of RootIO, a community information platform intended to support the creation of low budget and easy-to-use community radio stations in rural and isolated areas. The project is funded through an EU digital social innovation initiative that states the need "to capitalise fully on participatory innovation" [27] as one of its specific challenges. We will show how, in such a kind of social innovation project, intermediaries contribute not only in weaving together social relations with community members, but also in defining the technology. Therefore, we ask ourselves how do intermediaries, intended as "translators of interests and meaning between worlds of design and use", participate in a project of participatory social innovation with local communities? How do they contribute in shaping the design and use of technological innovation and in the definition of the related socio-technical infrastructure during the development of the project?

\section{INNOVATION, TECHNOLOGY, AND INTERMEDIARIES}

In this paper, we draw on research about innovation in commercial contexts and apply it to social innovation with local communities. We look at reflections on commercial innovation as a starting point in considering the importance of the relational dynamics with intermediaries when innovative artefacts are transferred and adopted in people's everyday life. After discussing innovation, we introduce the concept of social innovation stressing how social change comes with both innovative ideas and their implementation in the world. Finally, we will also describe how HCI and Participatory Design have considered the concept of intermediary, with a particular focus on social innovation processes.

There is agreement between researchers that innovation is not just the development of a good idea as an artefact but also its appropriation and use in people's life. Jan Fagerberg and colleagues, for instance, state that "Invention is the first occurrence of an idea for a new product or process, while innovation is the first attempt to carry it out into practice" [29:4]. The need for HCI to make more efforts to translate good ideas into practice is also stressed by Norman [48]. He describes how HCI research has little impact on innovation practice, primarily due to a mismatch of knowledge and skill sets between researchers (that seem disinterested in commercialisation), and practitioners (who consider researchers disconnected from the world). In their literature review on the relationship between HCI and innovation, Frohlich and Sarvas [30] describe how Norman's reasoning is partially biased by technological determinism. However, they also underline how HCI needs to focus not only on user research, technology research, and constructive design research, but also on "business research," to better understand how technologies "are packaged, marketed and assimilated into a technical and social context full of competing technologies" [30:715]. In the next section, we draw on innovation studies to introduce the category of intermediaries, as actors that are able to interconnect the area of research, design, and development of innovative artefacts with everyday practices.

\subsection{Introducing Intermediaries in Innovation}

Within commercial contexts, the adoption of innovative products or services does not involve direct interaction between designers, producers and users, but is often filtered by different individuals and or organisations, called intermediaries. Their role primarily relates to marketing, with intermediaries often described as "bridging the incompatibilities between the two (market) sides involved in a transaction by transformation of output attributes of the supply market side to appropriate input attributes of the demand market side." [52:51]. However, in the innovation and development of technology, the word "intermediary" is used in very different ways. Howells [32:720] literature review of innovation intermediation suggests an intermediary is:

"an organization or body that acts as an agent or broker in any aspect of the innovation process between two or more parties. Such intermediary activities include: helping to provide information about potential collaborators; brokering a transaction between two or more parties; acting as a mediator, or go-between, bodies or organizations that are already collaborating; and helping find advice, funding and support for the innovation outcomes of such collaborations."

Callon stressed the role of intermediaries in distributed actions [12] in techno-economic networks of human and non-human actors. For him, intermediaries are "anything passing between actors which defines the relationship between them" [11:134]. He identifies four types of intermediaries: texts, technical artefacts, human beings with skills and knowledge and finally money. Callon extends the concept of intermediaries to include non-human actants. Clausen and Gunn [16], who investigate participatory innovation $[7-10,42]$ of products and services in commercial contexts, show how intermediaries work to move knowledge in a process of innovation, as practices and objects [59]. They define intermediaries "as networks of social actors and objects mediating between stages in design processes" [16:77]. For them, intermediaries move and shape innovative ideas and, at the same time, are shaped through this process.

Stewart and Hyysalo [54] investigate how intermediaries facilitate user innovation, the development and appropriation of new technologies, focusing on the supply side. Unlike Callon's emphasis 
on the non-human, Stewart and Hyysalo emphasise that intermediaries are actors and organisations that facilitate the activities of institutional, technical, or physical contexts performing "as translators of interests and meaning between worlds of design and use and/or between supply, development, and emerging markets" [16:76]. It is important to underline that for Stewart and Hyysalo [54:297] intermediaries "attempt to configure the users, the context, the technology and the content, but they do not, and cannot define and control use or the technology". Keeping the other definitions in the background, and aware of the importance of the non-human elements in these processes, in the next section we will rely on Stewart and Hyysalo definition of intermediaries, since we are interested in how particular individuals and organisations involved in a social innovation project act as "translators of interests and meaning" between the technology developers and community members testing RootIO in the light of future appropriation.

\subsection{Observing Social Innovation in Practice}

Social innovation is a process concerned with "innovations that are social both in their ends and in their means" [44:35]. Two interrelated aspects of social innovation are, on one hand, the invention, design, development, and implementation of products and services to support solutions to social and environmental needs and market failures and, on the other, the influencing of social relations to deepen social empowerment and values such as democracy [44, 47]. This duality of meaning is also evident in design and HCI. Marie Kirstejn Aakjær, for instance, underlines how Drucker [25] defined social innovation as solely "innovations driven by social needs" [1:101]. Later, other authors (e.g. [5, 19]) added the second aspect, stressing how social innovation processes influence the reconfiguration of social relations and organisations. Manzini [39] prefers to draw a line between the design goal of finding answers to (problematic) social situations and attempting to produce social change through new social and economic models towards sustainability. In contemporary empirical reality, this differentiation tends to blur, as technology design more and more considers not only functionality but also wider socio-technical dimensions, including relations with institutions (e.g. [33]), renewed political economic configurations $[4,26]$ and, importantly, a combination of these elements in fostering alternative futures (e.g. [36]).

In the area of social innovation and technology, Participatory Design (henceforth, PD) is considered a useful approach to identify user needs and to foster social change through processes of infrastructuring (e.g. [5, 36, 40]). At the same time, several authors $[18,43,60]$ underlined how PD has suffered from a lack of attention on the concept of innovation itself. To foster (social) innovation, the co-creation of ideas is not enough, since it is necessary to consider how these ideas are implemented into products, services, or models, and how these artefacts are embraced, shaped, and used in the world. Clayton M. Christensen and colleagues [13], offering some guidelines to identify "catalytic innovations", state that "just because an organization has come up with a good idea for systemic social change doesn't mean that it will succeed in implementing that change", and it is important to "assess whether the group's business model can allow it" [13:6]. We suggest that a starting point to improve our understanding about this area of social innovation, is to analyse the role of intermediation in this process.

\subsection{HCI, PD, and the role of intermediaries in social innovation}

There are few HCI studies focusing on intermediaries and their role as translators between design, development, and use in technological innovation. Previous research does however, reflect on the fundamental role of translators [37], tailors [37, 58], local developers ("gardeners" [31]), IT technical supporters [14] and platform coordinators [6], in creating a local, shared technical environment, mediating between the various actors and technologies during early automation processes developed in the $90 \mathrm{~s}$.

In more recent literature, intermediation has been observed through different shapes and meanings (e.g. [23, 45, 46]). For instance, Nansen and colleagues [45] investigate processes of intermediation through proxy-users, agents that mediate people's engagement with technology. An example of a proxy-user is a family member with the skills to buy hardware and to download contents from the internet. Such intermediaries can enable others to perform activities, assert their identity by speaking on their behalf on social media, or inhabit the identity of another person online. For Dombrowski and colleagues [23] intermediaries are individuals who assist citizens to access and use e-government services: they are described as not simple users, because they use the technology on behalf of other people. The role of these intermediaries is fundamental in enabling citizens to engage with government programs, overcoming challenges of access and trust. What we learn from $\mathrm{HCI}$ is that the relationship that users have with the design and use of a technology can often be mediated by other actors and that individuals acting as proxies can become intermediaries supporting less skilled humans to engage in technological processes.

While this HCI research introduces the importance of people acting as "intermediaries" it does not apply this learning to the area of social innovation in communities.

Within PD and innovation, practices of intermediation differ again. As already mentioned, Clausen and Gunn [16] investigate the role of intermediary objects such as ethnographic provocations in processes of Participatory Innovation. This is a design approach used in commercial settings that focuses on creating "agonistic public spaces" [5] that enable conflict and tension [7] rather than consensus as a source of innovation inspiration. They particularly focus on the crossing of intentions of users and developers as a means of creating innovation, and the coming together of people and designers to tackle an issue of concern often defined as public formation [34, 55]. Participatory innovation is interested in conflictual conversations where new meanings, "in local interactions between people with different intentions" [8:122] emerge. While this focus on the qualities of conversation is of interest, the attention remains on commercial rather than geographical communities, the focus of our work. In addition, in our research we consider intermediaries as a category of human actors, individuals and organisations, involved in the innovation project, and not just an ethnographic representation of them, which is the case in participatory innovation in the commercial context. 
PD research also explores Institutioning $[15,33,56]$, that is the interaction between design and institutional frameworks: intermediation, in this case, is described as the ability of PD researchers and practitioners to "act strategically aiming to trigger institutional transformation" [56:3]. In this context, PD designers are intermediaries that mediate misunderstandings with institutions, when there is a lack of alignment of the design process with institutional cultures and norms. Cibin and colleagues [15] described how grassroots communities involve new external allies to face institutional constraints related to the participatory design of a new technology. However, the influence of intermediaries in kick starting the project and in shaping the design and use of the technology through the interaction between developers and community members has not yet been analysed in-depth.

In design and social innovation, organisations that mediate between designers and the real world are often positioned as allies, and described as social groups that need to be involved in the social innovation process. Dearden and colleagues [20] stress how critical computing must support the needs of "agencies concerned with emancipatory issues" [20:133]. Similarly, Teli and colleagues reflect on "which social groups can be relevant allies for PD researchers today" [57:38]. Lyle and colleagues [36] and Sciannamblo and colleagues [53] describe the work of local NGOs in "reaching out to the local population and establishing connections with local institutional bodies" in a project of participatory design for social innovation. It is underlined how these actors, close to our definition of intermediary, bring to the project specific goals and interests and also different knowledge, practices, ethical, and political agendas. For projects to be successful in creating social innovation, this body of research suggests that both the selection of partners and the construction of long-term relations is a key step to increase the possibilities of achieving socially meaningful innovation. However, these studies tend to focus on communities of interest and not on geographical communities, our focus.

Le Dantec and Fox [35]'s community HCI reflected on the challenges of PD within geographical communities and described the importance of "the work that occurs before the work: developing relationships, demonstrating commitments, and overcoming personal and institutional barriers" [35:1349]. They show how negotiating "productive partnerships" to have access to the community contributes to the construction of the community itself, and that for technologies to be useful for communities they must align with community needs and goals. However, in community settings a plurality of interests, histories, and goals contrasts it to the workplace, where it is easier to define a common goal and to identify specific roles and objectives. They suggest that the "work before the work" is time consuming. However, there is still a gap in understanding how intermediaries, intended as individuals and organisations who are "translators of interests and meaning between worlds of design and use", contribute to a participatory innovation project. Therefore, we ask ourselves: how do intermediaries participate in a project of participatory social innovation with local communities? How do they contribute in shaping the design and use of technological innovation and in the definition of the related socio-technical infrastructure during the development of the project?

To answer this question, we present and discuss the development of a project intended to support citizen engagement and media pluralism. We will describe the field deployments aimed at introducing and testing RootIO, a community information platform to support the creation of low budget and easy-to-use community radio stations in rural and isolated areas. We will introduce the main actors involved and their interactions, with a particular focus on the intermediaries and their activity to connect the group of designers, developers and researcher with members of the different communities.

\section{GRASSROOT WAVELENGTHS}

Grassroot Wavelengths [15] is a project aimed at participatory innovation in the domain of media pluralism that started in 2018 and will receive funding until the end of 2020. The main goal is to support the creation of a network of FM community radio stations in isolated areas across Europe, fostering collective action, community deliberation, linguistic diversity and the free flow of information into and out of discrete geographic communities. The project is based on RootIO, a free/open hardware and software platform [17] that allows the creation of low budget FM radio stations based on the internet, a cheap smartphone, an FM transmitter, and an antenna, without the need of a physical studio.

Grassroot Wavelengths has been testing and developing RootIO in three countries in Europe after it was designed and first deployed in Uganda. During 2018, the project's efforts mainly focused on getting the licenses for broadcasting in the different countries, involving the local communities, and setting the radio stations. In Ireland and Romania, stations have already started broadcasting and running their own programs. In Portugal, due to the possibility to obtain only short-term experimental transmission licenses and to some problems incurred in the project that we will describe later, the broadcasting of only a few events and programs have been possible and currently the transmissions are suspended. In each country, a different community partner (see Table 1), worked in the community to help set up the station, and to engage local citizens. In Ireland, there is also a research institution supporting this process. Those partners function as intermediaries between the project's designers and developers, and the local communities, the users, who will become the owners and managers of the stations (Figure 1 left). Since the proposal, the project has been interested not only in the development of the technology, but also in supporting the communities to identify good practices and new technological features that can allow the radio stations to be sustainable also after the conclusion of the project, both economically and from the governance point of view. In this case study, we will focus on the activities that have been taking place in two geographical contexts of the project, Romania and Ireland, and we will underline the main problems that incurred in Portugal and caused the suspension of the activities in that context.

\section{METHOD}

The first Romanian community involved is a fishing village of about 600 inhabitants within the Danube Delta Biosphere Reserve. The largest sectors of employment are fishing, forestry, small-scale cultivation, and tourism. The second is an inland commune of about 2800 inhabitants: economic activities in this area include agriculture, animal farming, beekeeping, fruit farming, and fish farming. 
Table 1: Entities involved in deployment of innovation, including Community Partners, Technical Designers and Developers, and Research Partners.

\begin{tabular}{llllll}
\hline & $\begin{array}{l}\text { Portuguese } \\
\text { Community Partner } \\
\text { (PorCP) }\end{array}$ & $\begin{array}{l}\text { Romanian Community } \\
\text { Partner (RomCP) }\end{array}$ & $\begin{array}{l}\text { Irish Community } \\
\text { Partner (IriCP) }\end{array}$ & $\begin{array}{l}\text { Technical Designers } \\
\text { and Developers } \\
\text { (TDD) }\end{array}$ & $\begin{array}{l}\text { Irish Research } \\
\text { Partner (IRP) }\end{array}$ \\
\hline Type & $\begin{array}{l}\text { Community } \\
\text { development entity }\end{array}$ & $\begin{array}{l}\text { 2 nonprofit watchdog } \\
\text { organisations }\end{array}$ & $\begin{array}{l}\text { Community } \\
\text { development entity }\end{array}$ & $\begin{array}{l}\text { Startup based on } \\
\text { innovation platform } \\
\text { + design research } \\
\text { institute }\end{array}$ & $\begin{array}{l}\text { Academic research } \\
\text { group }\end{array}$ \\
$\begin{array}{l}\text { Focus and } \\
\text { Skills }\end{array}$ & $\begin{array}{l}\text { social inclusion and } \\
\text { prevention of specific } \\
\text { social problems }\end{array}$ & $\begin{array}{l}\text { Journalism and media, } \\
\text { human rights, freedom } \\
\text { of expression. }\end{array}$ & $\begin{array}{l}\text { Community } \\
\text { development } \\
\text { activities to sustain } \\
\text { the island population. }\end{array}$ & $\begin{array}{l}\text { Innovation and ICT } \\
\text { for communities }\end{array}$ & $\begin{array}{l}\text { Research institute } \\
\text { and spin-off. } \\
\text { approaches to the } \\
\text { design of technology }\end{array}$ \\
$\begin{array}{l}\text { Goal in the } \\
\text { project }\end{array}$ & $\begin{array}{l}\text { Strengthening their } \\
\text { existing radio } \\
\text { activities. }\end{array}$ & $\begin{array}{l}\text { Radio for media } \\
\text { pluralism and political } \\
\text { activism. }\end{array}$ & $\begin{array}{l}\text { Radio as an activity } \\
\text { to keep the } \\
\text { community alive }\end{array}$ & $\begin{array}{l}\text { Testing and } \\
\text { improving the } \\
\text { technology }\end{array}$ & $\begin{array}{l}\text { Research, support } \\
\text { IriCP in community } \\
\text { engagement }\end{array}$ \\
Location & $\begin{array}{l}\text { Based within the } \\
\text { community }\end{array}$ & $\begin{array}{l}\text { Far from the } \\
\text { communities. }\end{array}$ & $\begin{array}{l}\text { Based within the } \\
\text { community }\end{array}$ & $\begin{array}{l}\text { Based close to the } \\
\text { Portuguese } \\
\text { communities }\end{array}$ & $\begin{array}{l}\text { Far from the } \\
\text { communities }\end{array}$ \\
\hline
\end{tabular}
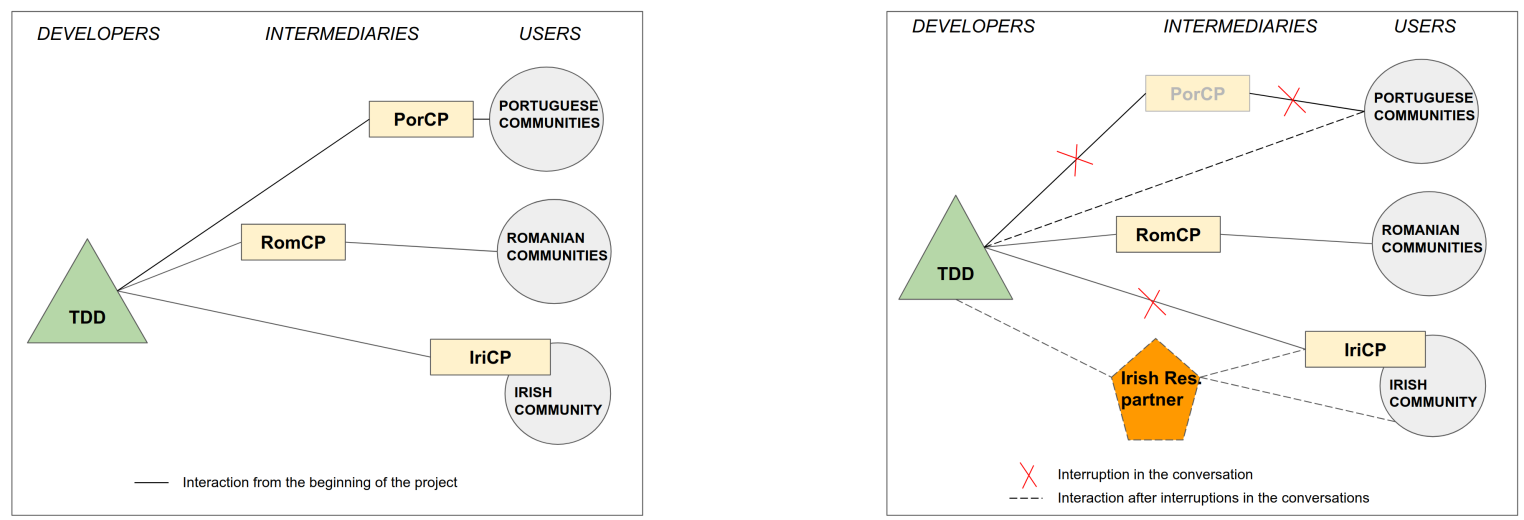

Figure 1: Comparison between the main actors' positions and dialogue at the beginning of the project (left) and after 2 years (right)

The Irish community involved is based on an island with a permanent population of under 200 people, which often trebles in the summertime. It lies $1.5 \mathrm{~km}$ off the mainland, and is connected by regular ferry services. The primary occupations are farming, fishing and associated industries.

In Portugal the project initially involved the community members of a municipality (about 10.000 inh.) and two civil parishes (about 10.000 and 2.000 inh.) of an island situated in the North Atlantic Ocean. The economic activities of this island are strongly based on tourism.

The authors actively take part in the project. The empirical data draws on three interviews conducted with representatives of RomCP and one with IriCP. Two authors from IRP were participant observers in Ireland during activities related to the setting up of the station, the recruitment of local volunteers, and the radio broadcasting in the community. Two authors from TDD had the possibility to observe the creation of the project and the consortium, and another author from TDD followed the activities in Portugal. In addition, we had access to material produced by the RomCP: field notes collected during the setting up of the station and activities of community engagement; a report with baseline information about the communities involved, and their media consumption habits. We also used internal and public project documentation as sources of empirical data. The internal documents are minutes of general assemblies, emails within the consortium, and project 
reports. The public documents are the Grant Agreement, the project deliverables, and the communication material. All data have been analysed through case study methodology [21]. The empirical data are presented chronologically, taking inspiration from biography of artefacts and biography of infrastructures approach [41, 50], as that allows to provide a description of the project unfolding and of how the project's human and non-human actors, and in particular the intermediaries, interact in order to set the socio-technical infrastructure supporting the innovation project in the different geographical localities. This approach will allow us to later discuss the role of intermediaries in the definition and pursuit of the project goals and how different positions, skills, and levels of trust influence this process.

\section{FINDINGS}

In the next sections, we offer a chronological description of the project unfolding in the communities of the different countries involved. We focus on the interactions and activities of the different intermediaries with their respective local community members and with the main actor involved in the development of RootIO and in part of the project research activities on the field: TDD (for a description of the actors see Table 1). We use the label TDD to group together two organisations part of the project consortium: a research centre involved in interactive technologies design and leader of the project consortium; a research spin-off start-up, owner and developer of RootIO. These organisations group the technical professionals, they are based in the same city in Portugal, and there is a strong intersection and interaction between the two staffs involved. For these reasons, and in order to make the narrative easier to follow, we decided to describe them as one organisation. For every country, we describe the dynamics that brought the intermediaries to be part of the consortium, and their participation in the project. For Portugal we offer just a short description of the dynamics that have brought to the current suspension of the pilot development.

\subsection{Portugal}

PorCP is a community organization in Portugal which facilitates social services for the elderly, and also operates two radio stations within a specific geographic area of a Portuguese island. PorCP's goal in the project was to strengthen their radio activities where they operate two radio stations. The relationship between PorCP and the project Consortium was complicated, as communications were very difficult, meetings were not attended, and TDD felt that in Portugal tasks were never really commenced. After some attempts undertaken by the General Assembly to save the situation through a clear articulation of what must be done by PorCP for it to remain part of the consortium, in Fall 2018 PorCP withdrew. It should be noted how the relation between TDD and PorCP was built in connection to the project proposal, as part of the efforts of TDD that included a lot of international researchers - to strengthen the community orientation of the project.

At the end of 2019, three people from TDD took the responsibility to start from scratch the process of engagement with people interested in introducing and testing RootIO in local communities. They started meetings with community members of two different civil parishes, where the technology was described. In one case this led to a group interested in creating a community radio station and to the broadcasting of a few programs. In the other location, it was not possible to assemble an interested core group as they expressed reluctance in getting involved and taking the responsibility on board. The efforts of the TDD team moved to another small town where initial feedback from community members was positive. At this point, however, contractual problems, mostly related to difficulties in the reallocation of the budget of PorCP, forced TDD to freeze activities in Portugal. The contract of the main TDD staff member engaging with the communities could not be renewed due to issues internal to TDD. This person had acted as intermediary with the community, rendering community engagement no longer feasible.

\subsection{Romania}

At project onset, the intention was that "in Romania, the focus will often be on political activism and investigative journalism" [28]. RomCP, the intermediary working with the communities, is composed of two watchdog organisations with expertise in human rights, freedom of expression, anti-discrimination media education, health care journalism, and patient advocacy. Some of the members also have basic skills in telecommunication and ICT. Both organisations are based far from the communities where the stations were launched (Table 1 and Figure 1 left). RomCP became part of the Consortium thanks to previous professional relations with TDD members, including a previous submission of a similar project proposal. These previous relations have unfolded over a number of years, becoming the backbone of RomCP participation in Grassroot Wavelengths.

In the first 9 months of the project, the intermediaries interacted with national institutions to get frequencies and licenses for broadcasting. Since there are no specific regulations for community radio in Romania, they applied for a commercial license that obliges them to follow many rules, including 24-hour broadcasting, seven days a week. As mentioned, the collaboration between TDD, and RomCP started before the project's proposal stage, and has remained collaborative during the long process of obtaining the license, as much paperwork involving specific technical data was needed. Once licenses were obtained, RomCP started the process of community involvement, to find volunteers for the management of the stations and the production of content.

"Basically, we attempted to go to meet the main stakeholders in the community, authorities, NGOs, businesses sometimes. And also people with higher education or people that seemed to us as being very vocal, articulate, that had potential for the radio. But we also talked to everybody - to as many people as we could. People on the street, people on the shops, we banged on doors, you know? We had help from a community assistant - helped us meet the elders of the community." (RomCP)

Through the organisation of public assemblies, with presentations and demos of RootIO, meetings with stakeholders, training on content production, and the use of RootIO, they can count now, 
in each respective location, on one group of seven volunteers collaborating with the stations.

"It's a slow thing. We first saw how we should do the things ourselves then we are slowly starting to give the things to do to the volunteers. You know? First doing the simple recording and sending through WhatsApp the simple things, second step, they edit their-selves, third step, put the things on the platform. And every time it's necessary to discuss with them and to teach them how they should approach all the interviews, or the people in these interviews - in terms of ethics and law because every time they need to have this in mind - that we don't break the law and the regulation." (RomCP)

In the last quotation, a RomCP member describes how they first had to practice and become familiar with the technology, in order then to show the volunteers how to use RootIO and to produce radio content, in a process that is described as very slow and made by different steps. In this process, we can see how this intermediary "translates" the definition of the technology adding some particular meanings coming from their journalistic background.

At the beginning of 2019, the antennae were mounted, and the stations were launched. RomCP has been responsible for installing software, sound and transmission hardware, and testing the system, as described in the next quotation:

"In the meantime we test all the functionality of the platform together with TDD. Because we follow the requirement of the project and follow TDD in this project, also for us - it is a challenge to see - how this new technology, new way to make radio different than the traditional way, with the mobile phone, performs" (RomCP)

The conversations between TDD, and RomCP took place not only during the project's meetings but also through bilateral interactions aimed at explaining the functioning of the platform, solving specific bugs, or discussing requests for new features able to solve issues emerged during the local testing. A WhatsApp group that includes TDD and RomCP proved fundamental for supporting these conversations.

In these interactions, RomCP often asked TDD to find a solution to some dysfunctions of RootIO that emerged during use in a context different from the context of its initial design. This request was intended to avoid problems during broadcasting, consequent problems with the regulatory framework and frustration of the volunteers involved. TDD sometimes had to re-explain to RomCP the rationale of RootIO from the developers' point of view, and the challenges for their small team related to a continuous 24/7 radio schedule, as exemplified in the next quotation:

"There is a disconnect here we need to address for sure. We are open to have a conversation with what you think is a must have and what is nice to have (in these next few months). We cannot address all the requests - we are a team of few people and can't be on 24 hours." (TDD addressing RomCP)
However, through this process, many problems in the platform have been solved, with "uptime" of intended programs rising from $45 \%$ to $95 \%$, and many customisations have been added to RootIO. On other occasions, RomCP was able to provide their own tech solutions. For instance, thanks to the support of technically proficient local volunteers, RomCP took the initiative of developing a technology that is able to stream the FM signal, allowing them to remotely check the functioning of the station.

During the continuation of the project and until the writing of this paper, there were other moments of contrast between RomCP and TDD, mainly due to the frustration created by the emergence of some new anomalies in RootIO and the RomCP's concern for a possible sanction from the regulator in case of a lack of stability in the broadcast. But the conversation between these actors has never stopped, the problems have always been fixed, and the commitment of RomCP in using RootIO is still strong.

\subsection{Ireland}

The project's primary intermediary in Ireland is IriCP, a local organisation responsible for community development on the island. IriCP were invited to participate in the project initially by the Irish Research Partner (IRP). The wider research team felt that the Irish Islands constituted a similarly peripheral place in Europe (at least geographically) to the Portuguese and Romanian community locations, which had already agreed to participate. IRP used local networks to make contact with IriCP, in order to ascertain whether they would be interested in participating in the project, the details of which had already been mostly decided. In first discussing participation in the project, IriCP were very enthusiastic about the potential for community radio in supporting community development on their own island, and the Irish islands more broadly.

All the members of IriCP belong to the geographical community (Figure 1), and are part of the community as insiders. The island population has been declining for generations, and one of the primary goals of the organisation is to sustain the population and keep the community viable, "through a range of initiatives which as well as creating employment, also serve to improve the quality of life for islanders, whilst also striving to protect the island's unique natural environment" [28]. The community radio is considered one of the ways they can achieve these goals. They also aimed to collect oral histories of the islands and preserve them for future generations, and to include those (either through migration, old age or ill health) who could not participate in community activities, through the radio.

IriCP's initiation to the project was due to take place at a General Assembly meeting in Portugal to launch the project. Due to high winds, the IriCP's representative was unable to attend as his flight ended up landing in mainland Portugal. The second General Assembly took place in Romania, and a community representative with sound recording experience attended on behalf of IriCP key personnel, who were unable to attend due to an increased workload over the summer months. Their first face to face meeting with developers took place a full year into the project.

Differently from IriCP, IRP is an academic research group interested in experience-centred design and community engagement and offered research and PD support to the overall project. In the second 
year of the project, this emphasis shifted to Ireland through field presence and an ethnographic approach to promote engagement. A researcher hired specifically to engage with the IriCP started in the second year of the project and began field work as the radio station was being established on the island.

In 2018, IriCP launched their community radio station via an online stream as part of a summer event, where they invited members of the community to introduce them to the radio. They also had a public meeting to invite local people who might be interested. A small number of people came forward - the majority of whom were interested in making content, rather than the technical aspects of community radio.

IriCP also sought support from local community radio stations who visited the island during their launch, and provided follow up training on radio interviewing skills and governance of radio stations. The first year of the project then IriCP focused on establishing a community radio and obtaining a temporary 30-day community radio licence from the Broadcasting Authority of Ireland (BAI). The process took place with some support from TDD and IRP, but the primary support came from the neighbouring community radio station engineer. IriCP received a temporary licence from the Broadcasting Authority of Ireland (BAI) in December 2018 and launched the station in March 2019, broadcasting on a range of Sundays throughout the year. A community radio committee was established, composed by IriCP and other community members: initial volunteers included media professionals with experience in radio, media production, and journalism.

In the run up to the broadcast, IriCP received five remote training sessions on how to use RootIO. They also installed the mast and antenna with the transmitter on top of the highest point on their island (in order for transmission to reach the surrounding areas) with support from the neighbouring community radio. Days before the broadcast, the mast snapped in high winds and the IriCP were again able to swiftly get support from the neighbouring community radio engineer in finding a replacement that was durable.

In March, IriCP reported trying using RootIO for broadcasts but having difficulty. They reported that the phone connected to the antenna (the radio station) continuously needed to be refreshed, leading to interruptions in transmission. It also meant that radio volunteers or IriCP representatives had to go up the hill on fourwheel drive or on foot (talking either 20 minutes or over an hour) in bad weather conditions to refresh the phone. From the developer perspective, they were not using the phone in the intended way and this was leading to the interruptions. Locals with experience in sound and radio felt that RootIO was not stable enough to ensure reliable broadcasting, and based on pressure from those with technical capacity in the community, IriCP made the decision to devise an alternative system to enable broadcasting. This, they felt, would enable them to get their community radio station off the ground, buy community support, and meet their licencing requirements for broadcasting.

In early visits to the community, an IRP representative explained to the community radio committee that the project was about the co-design of the technology together with the community and on making it work together, feeding back issues to TDD and refining them. An IriCP representative stated:
"The community thought that this project was all about community needs, and supporting the community to set up radio, we assumed the technology worked. We were told it had worked in Uganda - why isn't it working here? This is the first I have heard that the project is about the design of this technology." (Notes from radio committee meeting, March 2019)

Other community volunteers on the committee stated:

"The radio wouldn't have happened without the project, acknowledge that. Also we acknowledge though, it's been very time consuming and challenging" (notes from radio meeting, March 2019).

In addition in Ireland there is a rich heritage of community radio and commercial radio. IriCP felt overburdened by both piloting a new technology and feeding into the design processes, while also establishing a community radio station, meeting regulator demands, and community expectations for reliable radio broadcasting.

"[in Ireland] there is a high level of expectation among people who listen to radio for quality, [...] if you have something that's not reliable, that's not there when you say it's going to be there, or you have breakdowns or whatever, then people will lose interest and very very quickly, and I think that's vital and I think that that was partly probably the initial confidence issues in the context of our station with RootIO" (Neighbouring community radio support).

IriCP, together with some community volunteers innovated and developed an alternative system, which enables reliable broadcasting. However, the setup of this system mimics professional radio and is complex for non-experts to use: it requires significant editing, someone to physically be present at a specified time to schedule radio broadcasts, and someone to be familiar with the radio equipment used. Interestingly, these were some of the issues that RootIO was intended to address. Through the use of this labour demanding system, there is now an understanding by some that the RootIO's affordances (e.g. automated playlists, and hosting live on air using a basic phone) could benefit the community in the long-term to have a more accessible platform. As suggested by one of the community radio practitioners that supports IriCP:

"It's the requirement for somebody to be actually sitting in the studio for three hours on a Sunday, you know? You know, you've a presenter and you've got a technical person, so the technical person has to continue if they are going to continue with live broadcasting, it has to become self-operated. And to do that the system has to be simple to operate". (Neighbouring Community Radio station volunteer)

The use of a traditional system to broadcast entails an effort that a small group cannot sustainably bear, so he sees the possibility of a movement toward RootIO, or an alternative solution that could enable more people to be involved in the production side of the community radio and automation. However, this is also dependent on local interest. To counteract the overburdening of the community with "making the technology work and after a period of ethnographic observation that enabled a better understanding 
of the actors and the dynamics in action, IRP facilitated communication between TDD and IriCP, supporting the "translation" of each other's needs and intentions. This action has been a way to restart a conversation between the actors involved, as described in the next quotation:

\begin{abstract}
"We want to work with RootIO. What was happening at the start is if you bring new ideas to a community and it doesn't work technically - a small community will pull away very quickly. So we were lucky to have [the support from another radio station]. Now radio is viewed very positively in the community and we have a person who will work with RootIO to get over the issues. CRAOL was a great support. IRP has been a support. People trust [the two IRP's researchers working on the field] now." (IriCP member).
\end{abstract}

The excerpt summarizes how the lack of communication about the RootIO's stability between TDD and IriCP brought the latter to look for the support of the expert from a neighbouring radio station, and due to tension between one of the goals of the project (to pilot test a software platform) and their own goals (to provide a successful, trusted, reliable service to their community), they opted for the latter goal which was in line with their needs and capacity.

In the meantime, the increased presence of IRP's researchers on the field (Figure 1 right) fostered both IriCP and the other community members to create a stronger relationship with IRP and to put more effort in the collaboration on the implementation of RootIO. This resulted, for example, in TDD developing and providing an online training for IriCP and IRP on how to use the platform.

\section{DISCUSSION}

We presented a description of the unfolding of a social innovation project to introduce and test RootIO, a platform that supports the creation of community radio stations in local communities in three different countries. We observed the interactions and activities of the different actors involved in the local development of the project, and, in particular, we focused on answering the following questions: how do intermediaries participate in a project of participatory social innovation with local communities? How do they contribute in shaping the design and use of technological innovation and in the definition of the related socio-technical infrastructure during the development of the project?

First of all, intermediaries have a strong influence on the construction of the social infrastructure where the process of innovation is supposed to take place. To paraphrase Frohlich and Sarvas [28], they are responsible for the definition of the "business model" through which they find new "customers", in our case persuading community members to become volunteers for the radio station. RomCP members walking door to door to invite people to their meetings is emblematic of this fact. When PorCP leaves the project, it also takes away its "customer portfolio", the networks of community members in which the organisation was inserted. The difficulties to have a new reliable intermediary that can promote the use of the artefact within the communities bring the project to a suspension in Portugal. If social innovation deals with "innovations that are social both in their ends and in their means" [44:35], we can add that intermediaries not only contribute to the definition of the social base of the innovative process, as just shown, but also towards its social ends. The TDD project's objective to improve media pluralism and community deliberation, for instance, needed to find a deal with the IriCP's goal of community development.

We also find that in participatory social innovation processes with local communities, intermediaries influence the technology and its use, in opposition to the description offered by Stewart and Hyysalo of intermediaries as actors that "do not, and cannot control" [54:297] neither the artefacts nor its employment. Acting as proxy users [45] we find that intermediaries shape how the technology has to be understood and used by community members. In Romania, RomCP had to learn how RootIO works before explaining it to the community members. This translation brought the addition of investigative journalism, related to the background of the organisation. At the same time, the experience of some technologically proficient Romanian community members helped RomCP to produce new features for RootIO, the possibility of remote streaming, that became part of the design process. The IriCP's decision to substitute RootIO [51] with a different technology had an impact on the control of the artefact and its use. It is evident that the skills, but also the goals of the intermediaries, have a strong influence on how the technology is represented and translated in the communities.

As we will describe in more detail below, we find that these dynamics are influenced by the position of the intermediaries within the project, by their goals, and by the related possibilities to build trusted relationships with the other partners and with the technology itself. In the following section, we will describe in more detail the contribution of intermediaries in a participatory social innovation process within the community offering some suggestions that researchers and practitioners should consider.

\subsection{Intermediaries and the "work before the work"}

The "work before the work" that Le Dantec and Fox [35] described in relation to their research with geographical communities that share social norms and often have conflictual goals, introduces an important point for influencing social innovation processes in community settings. Whilst the work of intermediaries is important, part of their role is to promote the formation of a public [34], understood as an ensemble of developers, designers, and community members concerned with a common issue. Whilst this might seem easy on paper, in reality it is work that can be slow, tiresome and lengthy, but central to making things happen. We would extend Le Dantec and Fox's idea of the "work before the work" to also include intermediaries that will translate between communities and designers/developers. This means that intermediaries are responsible for the construction of stable relationships based on trust, skills, and knowledge in two different directions: with the developers, on one side, and with the communities, on the other.

In Romania, we see that some of the "work before the work" between TDD and RomCP took place years before the current project began as the people involved in the Romanian initiative had connections and developed shared understandings with TDD through jointly writing a previous (unfunded) proposal. RomCP and TDD goals were aligned but, at the same time, RomCP needed to start from scratch its relationship with the two communities. 
This meant that initially all the development and management of the radio stations was on their shoulders. RomCP acts as a kind of proxy user between the community and the developers. This concept of intermediary we propose extends, and includes, the idea of proxy user as a form of intermediation advanced by Nansen and colleagues [45]. RomCP is part of a phased handover to the actual geographic communities in which the community radios stations are established and it offers a new type of community innovation in which intermediaries act as proxies to enable a public to form around the innovative product, in this case the radio platform.

In Portugal, we see that there was a lack of synergy between PorCP and TDD and this interrupted the connection between TDD and the local communities. Some members of TDD tried to substitute PorCP through community outreach trying to do the "work before the work" with some rural communities. However, as we saw, this kind of activity needs a lot of time and effort, as well as resources. When the staff with the primary connection to the communities changed jobs, this collaboration was brought to an end, due to insufficient capacity to continue. This fact suggests the importance of resourcing for intermediaries, that is finding solutions that guarantee the presence of intermediaries for (at least) all the duration of the project avoiding precariousness.

In Ireland, at the beginning of the project IriCP had strong connections with the community, as it is part of that community. It did not know or have a connection with TDD and the initial connection was opportunistic and based on an understanding that RootIO could facilitate local connections and preserve local heritage. In contrast to the Romanian case, IriCP and TDD did not have the possibility to build trust in face to face encounters and to share knowledge and expectations, namely, to do the "work before the work". They were not prepared for what Dittrich et al. [22] suggest is the everyday efforts of making technology work that takes place when innovation is "in the wild", and took a pragmatic approach to substitute RootIO with off the shelf radio broadcasting technologies with the support of local professionals to meet their local goals.

\subsection{Being aware of intermediaries' stakes and objectives}

Discussing a European project similar in intent and approach to the one just described, Lyle and colleagues [36] described how the project objectives stated in the Grant Agreement could be concretely translated into a progressive agenda combining different strategic and tactical actions through which the different partners build mutual relations while trying to pursue their own agendas. In Grassroot Wavelengths, we found that intermediaries are fundamental in trying to find a synthesis between the different partners' objectives and in this process the level of trust between technicians and communities is very important.

The Romanian intermediaries are motivated to increase freedom of speech and media pluralism in a media landscape dominated by oligarchs. In the conversation with TDD, tensions are arising concerning the design of RootIO in a way that conforms to the regulatory framework supported in that country and the background of the intermediaries. Nonetheless, there is a desire from RomCP to conform to the project goals of implementing the platform as intended, e.g. radio without a studio and using live call-in features.
In contrast, the Irish case is motivated by the development of the island community, supporting inclusion in community activities, and preserving heritage. For the Irish intermediaries, media pluralism is not a motivation since there is a strong heritage of community radio in Ireland. As a consequence to this strong tradition, an aspiration towards a similar sound to commercial radio is emphasised by professionals supporting the community radio process. Even if IriCP has a strong commitment to the project goal of creating a community radio station, this does not necessarily liaise constructively with the technology provider. The divergent opinion on the rationale of Grassroot Wavelengths is one of the reasons that created a friction between TDD and IriCP and that needed the intervention of new intermediaries.

\subsection{Skillset, conflict and the need for new intermediaries}

In Romania, RomCP acts as an intermediary between community members and the project's developers, and is equipped with a basic knowledge related to ICT and telecommunication that allows the organisation to find the solutions to the technical issues emerged during the licensing process and the station setting. Through a continuous conversation with TDD, the technology has been modified and appropriated. Moments of conflict were not suppressed, but discussed, and gave an essential contribution to the accomplishment of this goal.

In the Irish case, when conflict emerged the conversation became stunted because TDD and IriCP spoke different languages, and goals and positions did not initially change. Initially, IRP was not equipped with the right skills and knowledge about the context and so not considered reliable to offer trusted support, which was met by a new intermediary. The Irish context sought support from neighbouring community radio experts, who provided hardware and software options, and supported seamless sounding radio content production, when RootIO was still daunting for the IriCP to start using. Training and demonstrations provided by these new intermediaries were vital in shaping the station's outlook and in finding reliable solutions for broadcasting radio. The development of the project in Romania confirms how innovation can be the result of conflictual conversations and tension [7, 8] between the actors involved.

However, the Irish case shows how this is possible only if all the actors involved in the conversation own the tools to understand and trust each other. In particular, the intermediaries need to trust the technology they have to promote. This trust can be fostered through a very slow process. It is fundamental to assess the skills and knowledge of the intermediaries and to organise a training plan to teach how to use the technology, based also on face to face meetings where the developers can transmit their confidence on the technology. For several reasons, sometimes also due to contingency, this activity was postponed in Ireland pushing IriCP and their community to move to a different technology described as more stable by their expert neighbours. 


\subsection{Intermediaries position and the support of ethnography}

It is important to underline that different goals and levels of trust may partly be influenced by the position of the intermediaries in the space of interaction between developers and users. In Romania, the intermediaries are based outside of the community and had the possibility to have a strong dialogue with TDD during the license application process. In Ireland, the intermediaries form part of the community and thus are sensitive towards community pride, in line with previous research showing how to introduce a new technology into a very small micro-society on a rural island is a challenge [51]. In the early days, when the intermediaries lost faith in the reliability of RootIO and were under institutional pressure for reliable broadcasting, they opted for a pragmatic off-the-shelf solution that is facilitated by the local media experts on the ground, who are members of the community or close neighbours. The result was that a public [34] was formed but around different goals than the wider project. This situation created a distance from TDD that needed to be filled by the presence of another intermediary. Once IRP managed to spend a longer time with IriCP and the community members and to become a trusted partner for them, the conversation between the latter and TDD could start again thanks to the translation of a new intermediary. The information collected through ethnographic work in the island allowed IRP to better understand how the actors involved had different perspectives and representation of the situation as the basis of their conflict [8] and tensions [7] without conversation.

\section{CONCLUSION}

In this paper we investigated the contribution of intermediaries in shaping participatory social innovation. Intermediaries were intended as individuals or organisations acting as "translators of interests and meaning between worlds of design and use". Drawing from research on innovation in commercial contexts, the main questions discussed were: how do intermediaries participate in a project of participatory top-down social innovation with local communities? How do they contribute in shaping the design and use of technological innovation and in the definition of the related sociotechnical infrastructure during the development of the project? We provided an initial answer through the analysis of the pilot developments of a European project aimed at introducing and developing a technology that supports the creation of community radio in rural and isolated areas. We observed how in these contexts intermediaries offer a strong contribution in the definition of the social base and ends of the innovation process. In addition, we found that intermediaries, acting as proxy-users, can influence the technology and its use, contrary to previous claims in the literature.

Part of the intermediaries' role is to promote the formation of a public, understood as an ensemble of developers, designers, and community members concerned with the same issue. We found that these dynamics are influenced by the position of the intermediaries within the project, by their goals, and by the construction of stable relationships, based on trust, skills, and knowledge, both with the developers and communities, trying to find a synthesis between the different partners' objectives. We observed that in order to produce innovation through conflictual conversations, the actors involved need to share some skillsets that allow them to trust the technology proposed. Face to face training is fundamental for this purpose together with the use of ethnography to understand how the partners involved interpret differently the goal of the project. Future research, in projects with different configurations, is needed to deepen the understanding of the role of intermediaries in design processes for social innovation that, as we have shown, are related to the diversity of goals, positions in the project structures, and trust-based relations.

\section{ACKNOWLEDGMENTS}

The Grassroot Wavelengths Project has received funding from the European Union's Horizon 2020 Research and Innovation Program under Grant Agreement No 780890.

\section{REFERENCES}

[1] Marie Kirstejn Aakjær and Eva Brandt. 2012. Social innovation within prison service. In Proceedings of the 12th Participatory Design Conference: Exploratory Papers, Workshop Descriptions, Industry Cases - Volume 2 (PDC '12), 101-104. https://doi.org/10.1145/2348144.2348177

[2] Madeleine Akrich, Michel Callon, Bruno Latour, and Adrian Monaghan. 2002. The key to success in innovation part i: the art of interessement. International fournal of Innovation Management 06, 02: 187-206. https://doi.org/10.1142/ S1363919602000550

[3] Madeleine Akrich, Michel Callon, Bruno Latour, and Adrian Monaghan. 2002. The key to success in innovation part ii: the art of choosing good spokespersons. International fournal of Innovation Management 06, 02: 207-225. https://doi.org/ 10.1142/S1363919602000562

[4] Gabriela Avram, Jaz Hee-jeong Choi, Stefano De Paoli, Ann Light, Peter Lyle, and Maurizio Teli. 2019. Repositioning CoDesign in the age of platform capitalism: from sharing to caring. CoDesign 15, 3: 185-191. https://doi.org/10.1080/15710882. 2019.1638063

[5] Erling Björgvinsson, Pelle Ehn, and Per-Anders Hillgren. 2010. Participatory design and "democratizing innovation." In Proceedings of the 11th Biennial Participatory Design Conference (PDC '10), 41-50. https://doi.org/10.1145/1900441.1900448

[6] Susanne Bødker. 2000. Coordinating technical support platforms. Communications of the ACM 43, 11es: 5-es. https://doi.org/10.1145/352515.352520

[7] Laurens Boer and Jared Donovan. 2012. Provotypes for participatory innovation. In Proceedings of the Designing Interactive Systems Conference (DIS '12), 388-397. https://doi.org/10.1145/2317956.2318014

[8] Jacob Buur and Henry Larsen. 2010. The quality of conversations in participatory innovation. CoDesign 6, 3: 121-138. https://doi.org/10.1080/15710882.2010.533185

[9] Jacob Buur and Ben Matthews. 2008. Participatory innovation. International fournal of Innovation Management 12, 03: 255-273. https://doi.org/10.1142/ S1363919608001996

[10] Jacob Buur and Ben Matthews. 2008. Participatory innovation: a research agenda. In Proceedings of the Tenth Anniversary Conference on Participatory Design 2008 (PDC '08), 186-189.

[11] Michel Callon. 1990. Techno-economic Networks and Irreversibility: The Sociological Review. Retrieved May 4, 2020 from https://journals.sagepub.com/doi/10. 1111/j.1467-954X.1990.tb03351.x

[12] Michel Callon. 2004. The role of hybrid communities and socio-technical arrangements in the participatory design. fournal of the center for information studies 5 , 3: 3-10.

[13] Clayton M. Christensen, Heiner Baumann, Rudy Ruggles, and Thomas M. Sadtler. 2006. Disruptive Innovation for Social Change. Harvard Business Review. Retrieved May 4, 2020 from https://hbr.org/2006/12/disruptive-innovation-forsocial-change

[14] Ellen Christiansen. 1997. Gardening: A metaphor for sustainability in information technology-technical support. In An Ethical Global Information Society: Culture and democracy revisited, Jacques Berleur and Diane Whitehouse (eds.). Springer US, Boston, MA, 171-185. https://doi.org/10.1007/978-0-387-35327-2_16

[15] Roberto Cibin, Maurizio Teli, and Sarah Robinson. 2019. Institutioning and Community Radio. A comparative perspective. In Proceedings of the 9th International Conference on Communities \& Technologies - Transforming Communities (C\&T'19), 143-154. https://doi.org/10.1145/3328320.3328392

[16] Christian Clausen and Wendy Gunn. 2015. From the Social Shaping of Technology to the Staging of Temporary Spaces of Innovation - A Case of Participatory Innovation. Science \& Technology Studies. Retrieved May 4, 2020 from https: //sciencetechnologystudies.journal.fi/article/view/55358 
[17] Chris Csíkszentmihályi and Jude Mukundane. 2016. RootIO: ICT + telephony for grassroots radio. In2016 IST-Africa Week Conference, 1-13. https://doi.org/10. 1109/ISTAFRICA.2016.7530700

[18] Peter Dalsgaard and Kim Halskov. 2010. Innovation in participatory design. In Proceedings of the 11th Biennial Participatory Design Conference (PDC '10), 281282. https://doi.org/10.1145/1900441.1900508

[19] Lotte Darsø. 2012. Innovation Competency - An Essential Organizational Asset In Employee-Driven Innovation: A New Approach, Steen Høyrup, Maria BonnafousBoucher, Cathrine Hasse, Maja Lotz and Kirsten Møller (eds.). Palgrave Macmillan UK, London, 108-126. https://doi.org/10.1057/9781137014764_6

[20] Andy Dearden, Steve Walker, and Leon Watts. 2005. Choosing friends carefully: allies for critical computing. In Proceedings of the 4th decennial conference on Critical computing: between sense and sensibility (CC '05), 133-136. https://doi org/10.1145/1094562.1094582

[21] Norman K. Denzin and Yvonna S. Lincoln. 2017. The SAGE Handbook of Qualitative Research. SAGE Publications.

[22] Yvonne Dittrich, Sara Eriksén, and Christina Hansson. 2002. PD in the Wild; Evolving Practices of Design in Use.

[23] Lynn Dombrowski, Gillian R. Hayes, Melissa Mazmanian, and Amy Voida. 2014 E-government intermediaries and the challenges of access and trust. ACM Trans. Comput.-Hum. Interact.21, 2. Retrieved April 16, 2020 from https://doi.org/10. $1145 / 2559985$

[24] Andy Dow, Rob Comber, and John Vines. 2019. Communities to the left of me, bureaucrats to the right. . . here I am, stuck in the middle. Interactions 26, 5: 26-33. https://doi.org/10.1145/3351735

[25] Peter Drucker. 2012. Innovation and Entrepreneurship. Routledge.

[26] Hamid R. Ekbia and Bonnie A. Nardi. 2017. Heteromation, and Other Stories of Computing and Capitalism. The MIT Press.

[27] European Commission. 2015. Collective Awareness Platforms for Sustain ability and Social Innovation - Horizon 2020 - Information and Communication Technologies Call - H2020-ICT-2016-2017. Retrieved October 10, 2019 from https://ec.europa.eu/info/funding-tenders/opportunities/portal/ screen/opportunities/topic-details/ict-11-2017

[28] European Commission. 2018. Grant Agreement - Grassroot Wavelengths

[29] Jan Fagerberg, David C. Mowery, and Richard R. Nelson. 2005. The Oxford handbook of innovation. Oxford university press.

[30] David M. Frohlich and Risto Sarvas. 2011. HCI and innovation. In CHI '11 Extended Abstracts on Human Factors in Computing Systems (CHI EA '11), 713-728. https: //doi.org/10.1145/1979742.1979670

[31] Michelle Gantt and Bonnie A. Nardi. 1992. Gardeners and gurus: patterns of cooperation among CAD users. In Proceedings of the SIGCHI Conference on Human Factors in Computing Systems (CHI '92), 107-117. https://doi.org/10.1145/142750. 142767

[32] Jeremy Howells. 2006. Intermediation and the role of intermediaries in innovation. Research Policy 35, 5: 715-728. https://doi.org/10.1016/j.respol.2006.03.005

[33] Liesbeth Huybrechts, Henric Benesch, and Jon Geib. 2017. Institutioning: Participatory Design, Co-Design and the public realm. CoDesign 13, 3: 148-159. https://doi.org/10.1080/15710882.2017.1355006

[34] Christopher A. Le Dantec. 2016. Designing Publics. The MIT Press.

[35] Christopher A. Le Dantec and Sarah Fox. 2015. Strangers at the Gate: Gaining Access, Building Rapport, and Co-Constructing Community-Based Research. In Proceedings of the 18th ACM Conference on Computer Supported Cooperative Work \& Social Computing (CSCW '15), 1348-1358. https://doi.org/10.1145/2675133. 2675147

[36] Peter Lyle, Mariacristina Sciannamblo, and Maurizio Teli. 2018. Fostering Commonfare. Infrastructuring Autonomous Social Collaboration. 452. https://doi.org/ $10.1145 / 3173574.3174026$

[37] Allan MacLean, Kathleen Carter, Lennart Lövstrand, and Thomas Moran. 1990. User-tailorable systems: pressing the issues with buttons. In Proceedings of the SIGCHI Conference on Human Factors in Computing Systems (CHI '90), 175-182. https://doi.org/10.1145/97243.97271

[38] Ezio Manzini. 2014. Making Things Happen: Social Innovation and Design. Design Issues 30, 1: 57-66.

[39] Ezio Manzini. 2015. Design, When Everybody Designs: An Introduction to Design for Social Innovation. MIT Press.

[40] Ezio Manzini and Francesca Rizzo. 2011. Small projects/large changes: Participatory design as an open participated process. CoDesign 7, 3-4: 199-215. https://doi.org/10.1080/15710882.2011.630472
[41] Maria Menendez-Blanco, Antonella De Angeli, and Maurizio Teli. 2017. Biography of a Design Project through the Lens of a Facebook Page. Computer Supported Cooperative Work (CSCW)26, 1: 71-96. https://doi.org/10.1007/s10606-017-9270-4

[42] Robb Mitchell and Jacob Buur. 2010. Tangible business model sketches to support participatory innovation. In Proceedings of the 1st DESIRE Network Conference on Creativity and Innovation in Design (DESIRE '10), 29-33.

[43] Nirmal Morjaria, Tracy Ross, and Andrew May. 2013. Fostering social innovation: identifying lead users for participatory design. In Proceedings of the Biannual Conference of the Italian Chapter of SIGCHI (CHItaly '13), 1-9. https://doi.org/10. $1145 / 2499149.2499177$

[44] Geoff Mulgan. 2012. The Theoretical Foundations of Social Innovation. In Social Innovation: Blurring Boundaries to Reconfigure Markets, Alex Nicholls and Alex Murdock (eds.). Palgrave Macmillan UK, London, 33-65. https://doi.org/10.1057/ 9780230367098_2

[45] Bjorn Nansen, Michael Arnold, Marcus Carter, Rowan Wilken, Jenny Kennedy, and Martin Gibbs. 2015. Proxy Users, Use By Proxy: Mapping Forms of Intermediary Interaction. In Proceedings of the Annual Meeting of the Australian Special Interest Group for Computer Human Interaction (OzCHI '15), 294-298. https://doi.org/10.1145/2838739.2838789

[46] A. F. Newell, M. E. Morgan, P. Gregor, and A. Carmichael. 2006. Theatre as an intermediary between users and CHI designers. In CHI '06 Extended Abstracts on Human Factors in Computing Systems (CHI EA ’06), 111-116. https://doi.org/10. $1145 / 1125451.1125479$

[47] Alex Nicholls and Alex Murdock. 2012. The Nature of Social Innovation. In Social Innovation: Blurring Boundaries to Reconfigure Markets, Alex Nicholls and Alex Murdock (eds.). Palgrave Macmillan UK, London, 1-30. https://doi.org/10.1057/ 9780230367098_1

[48] Donald A. Norman. 2010. The research-practice gap: the need for translational developers. Interactions 17, 4: 9-12. https://doi.org/10.1145/1806491.1806494

[49] Alexander Osterwalder and Yves Pigneur. 2010. Business model generation: a handbook for visionaries, game changers, and challengers. John Wiley \& Sons.

[50] Neil Pollock and Robin Williams. 2010. e-Infrastructures: How Do We Know and Understand Them? Strategic Ethnography and the Biography of Artefacts. Computer Supported Cooperative Work (CSCW)19, 6: 521-556. https://doi.org/10. 1007/s10606-010-9129-4

[51] Sarah Robinson, Nicola J. Bidwell, Laura Maye, Nadia Pantidi, and Conor Linehan. 2020. Participation through substituting and refusing. In Proceedings of the 16th Participatory Design Conference PDC2020 (Manizales, Colombia) Vol. 2.

[52] Frank Rose. 1999. The economics, concept, and design of information intermediaries: A theoretic approach. Physica-Verlag Heidelberg.

[53] Mariacristina Sciannamblo, Peter Lyle, and Maurizio Teli. 2018. Fostering Commonfare. Entanglements Between Participatory Design and Feminism. Proceedings of DRS 2018: 458-471.

[54] James Stewart and Sampsa Hyysalo. 2008. Intermediaries, users and social learning in technological innovation. International fournal of Innovation Management (ijim)12: 295-325. https://doi.org/10.1142/S1363919608002035

[55] Maurizio Teli, Silvia Bordin, María Menéndez Blanco, Giusi Orabona, and Antonella De Angeli. 2015. Public design of digital commons in urban places: A case study. International fournal of Human-Computer Studies 81: 17-30. https: //doi.org/10.1016/j.ijhcs.2015.02.003

[56] Maurizio Teli, Marcus Foth, Mariacristina Sciannamblo, Irina Anastasiu, and Peter Lyle. 2020. Tales of Institutioning and Commoning - Participatory Design Processes with a Strategic and Tactical Perspective. In Proceedings of the 16th Participatory Design Conference PDC2020 (Manizales, Colombia).

[57] Maurizio Teli, Linda Tonolli, Angela Di Fiore, and Vincenzo D'Andrea. 2019. Computing and the common: Learning from Participatory Design in the age of platform capitalism. Università degli Studi di Trent. https://doi.org/10.5281/zenodo.3228359

[58] Randall H. Trigg and Susanne Bødker. 1994. From implementation to design: tailoring and the emergence of systematization in CSCW. In Proceedings of the 1994 ACM conference on Computer supported cooperative work (CSCW '94), 45-54. https://doi.org/10.1145/192844.192869

[59] Dominique Vinck and Alain Jeantet. 1995. Mediating and Commissioning Objects in the Sociotechnical Process of Product Design: a conceptual approach. In Designs, Networks and Strategies, Donald Maclean, Paolo Saviotti and Dominique Vinck (eds.). Directorate General Science, R\&D, 111-129. Retrieved from https://halshs.archives-ouvertes.fr/halshs-00273437

[60] Andrew Warr and Eamonn O'Neill. 2004. Getting creative with participatory design. In Proceedings of the 8th Conference on Participatory Design (PDC ) 2004, Toronto, Canada. 